\title{
Diseño de Mundos-Historia
}

\section{StoryWorld Design}

\author{
Coordinadores del número: \\ Beatriz Legerén Lago \\ Profesora Contratada Doctora Interina \\ (Universidad de Vigo) \\ España \\ blegeren@uvigo.es \\ http://orcid.org/0000-0001-6169-0875 \\ Nelson Zagalo \\ Profesor Asociado \\ (Universidad de Aveiro) \\ Portugal \\ nzagalo@ua.pt \\ https://orcid.org/0000-0002-5478-0650
}

\section{DATOS DEL NÚMERO}

Fecha de publicación: 1 de enero de 2019

Editores de la revista: Francisco García García (Catedrático de Comunicación Audiovisual y Publicidad en la UCM) y Manuel Gértrudix Barrio (Profesor Titular de Comunicación Digital en la Universidad Rey Juan Carlos)

Coordinadores del número: Beatriz Legerén Lago (Profesora Ayudante Doctora, Universidad de Vigo), y Nelson Zagalo (Profesor Asociado, Universidad de Aveiro)

Para citar este artículo: Legerén Lago, B. y Zagalo, N. (2019). Diseño de Mundos-Historia. Presentación, Icono 14, 17 (1), 1-4. doi: 10.7195/ri14.v17i1.1306 


\section{Resumen}

La digitalización afecta no sólo al consumo, sino también a la creación. Las historias no deben diseñarse solo para un medio (pantalla). Como creadores ya no sólo podemos pensar en un medio, sino que debemos pensar en su relación con el ecosistema de los medios, con independencia del futuro en el que nuestras creaciones se desarrollen, hoy en día es necesario pensar la producción narrativa más en términos de universo ficcional y menos en términos de historia cerrada.

Palabras clave: Transmedia; Elastic Storyworld; Ecosistema mediatico; Narracion Interactiva; Multiples pantallas

\section{Abstract}

Digitization affects not only consumption, but also creation. Stories should not be designed only for a medium (screen). As creators we can no longer only think of a medium, we must think about its relationship with the ecosystem of the media, regardless of the future in which our creations are developed. Nowadays it is necessary to think the narrative production more in terms of fictional universe -storyworld-and less in terms of closed history.

Key Words: Transmedial; Elastic storyworld; Media ecosystem; Interactive narrative; Multiple screens

\section{Presentación}

La digitalización afecta no sólo al consumo, sino también a la creación. Las historias no deben diseñarse solo para un medio (pantalla). Como creadores ya no sólo podemos pensar en un medio, sino que debemos pensar en su relación con el ecosistema de los medios, con independencia del futuro en el que nuestras creaciones se desarrollen, hoy en día es necesario pensar la producción narrativa más en términos de universo ficcional y menos en términos de historia cerrada.

Robert Pratten el autor invitado nos intodue el concepto de "elastics storyworld "en contraposición al persistente storyworld: un mundo que se adpata a las ac- 
ciones inesperadas del "view-user-player"pero que también recupera su sentido primigenio pasado un tiempo.

Sin ir más lejos, en años recientes hemos cambiado nuestro propio discurso, dejando de hablar de escribir narrativa para hablar de diseñar narrativa. Pero sobre todo en la necesidad de crear narraciones que funcionen como sistemas orgánicos capaces de permitir la ligazón entre diferentes historias, multiplicando las perspectivas, originando universos.

Los contenidos audiovisuales, se ven actualmente canalizados a través de numerosos soportes que favorecen el acceso ininterrumpido a un universo inagotable de piezas de muy distinta naturaleza. modalidades de comunicación etiquetadas como transmedia ha potenciado la consecución de experiencias que gravitan alrededor de los denominados transmedial worlds, mundos ficcionales que no solo favorecen la continuidad narrativa a través de los propios relatos, tal como nos demuestran los autores del artículo (R)evolución del ecosistema mediático contemporáneo.

De tal forma que las audiencias antes "medio-centristas" ahora se convierten en "narrativo-centristas". Provocando la aparición de un nuevo perfil de consumidor el vup (view-user-player).

Ello ha provocado que un cambio en las necesidades de las empresas productoras, ya que necesitan crear nueva propiedad intelectual. Nuevos productos para mantener todas las redes de contenidos en funcionamiento que también supone un aumento de producción. La facilidad del espectador para identificarse, de sentir empatía, y de querer acceder a más del mismo universo, promueve que cada vez más, cada nueva historia no pueda ser sólo una historia, sino que deba tener condiciones para su apertura a nuevos universos narrativos completos.

En el artículo "El Storyworld en la narrativa de los Juegos Documentales Interactivos: el caso del Fort McMoney", los autores trabajan sobre el desarrollo de modelos que conciben el espacio como lugar cardinal donde establecer relaciones esenciales entre elementos narrativos, se relaciona con los cambios operados en el rol del espectador, que deviene usuario-jugador, gracias al desarrollo de narrativas laberínticas. Revalorizar los "trayectos" narrativos posibilitando al usuario el acceso a ese mundo, realizar recorridos 
uni o multiplataforma o transitar las tramas, resultan fundamentales para entender en toda su magnitud los fenómenos de expansión narrativa y de storyworld.

Por otra parte, no podemos olvidar que el mundo de la comunicación abandono el paradigma unidirecional de la creación, como tal no podemos pensar en emisor/ autor y receptor, sino en emisor/ autor para emisor / autor. Es decir, pensar que los universos ficcionales no terminan en el momento de ser estrenados, sino que es ahí cuando realmente comienzan, puesto que dependen de cómo se creen se irán apropiando y dando continuidad incluso en sus comunidades.

Sobre este tema han ahondado los autores del artículo "Narraciones transmedia, música y videojuegos: el caso de Los ríos de Alice de Vetusta Morla y Delirium Studios" donde se analiza la producción y expansión transmedia de una aplicación que combina música y videojuego y que ha contado con contenidos generados por los usuarios (UGC) creados por ellos y distribuidos públicamente, ser contenidos creativos, y haber sido creados fuera de las rutinas profesionales de las corporaciones.

En el artículo "Realidad virtual, publicidad y menores de edad", los autores trabajan con la realidad virtual como discurso más allá de lo tecnológico con creciente visibilidad en todos los ámbitos sociales, conformándose como uno de los protagonistas de la cibercultura. Remarcando que la publicidad no es ajena a este auge del relato inmersivo y empieza a ser habitual que campañas con enfoque transmedia empleen este recurso frente a otras narrativas y canales de difusión. Para ello trabajan con el caso de promoción de la producción "El libro de la Selva".

Para finalizar este recorrido por los universos transmedia, en "El videoarte, creatividad salvaje y disección social: estudio de caso Loop Fear Barcelona 2013", la autora analiza como la práctica del vídeo ha evolucionado en continua discordia con el lenguaje televisivo introduciendo términos como "composición multimedia". Y como vídeoarte muestra de manera perturbadora una creatividad que podríamos denominar "salvaje" y se le considera pionero del carácter híbrido transmediático.

\section{(c) $\underset{\mathrm{EY}}{(\mathrm{i})}$}

Esta obra está bajo una licencia de Creative Commons Reconocimiento-NoComercial 4.0 Internacional. 